\section{THE KINEMATICS OF MACHINERY} II.

A FTER the discussion of lower pairs of elements, higher pairs are considered, such, for instance, as that of the duangle and triangle, the motions of which with respect to each other are thoroughly described. One of the most useful sections of the book, and which we strongly recommend to the attention of engineers and machinists, is that on the General Determination of Profiles of Elements for a given Motion (p. 146). To the practical mechanic who has read the discussion on the different pairs of elements, it must appear that there are some motions taking place in machines in the required manner that are not constrained completely by the resistance of the parts of the machine, such, for example, as the motion of the bed-plate of a planing machine in the $V$ guides, and it is obvious that this motion would not be constrained to take place in the required manner if the machine were turned upside down. The constraint only in certain positions of the pair of elements is called force closure, and the pair is called an incomplete pair of elements, the determination of the motion in the required

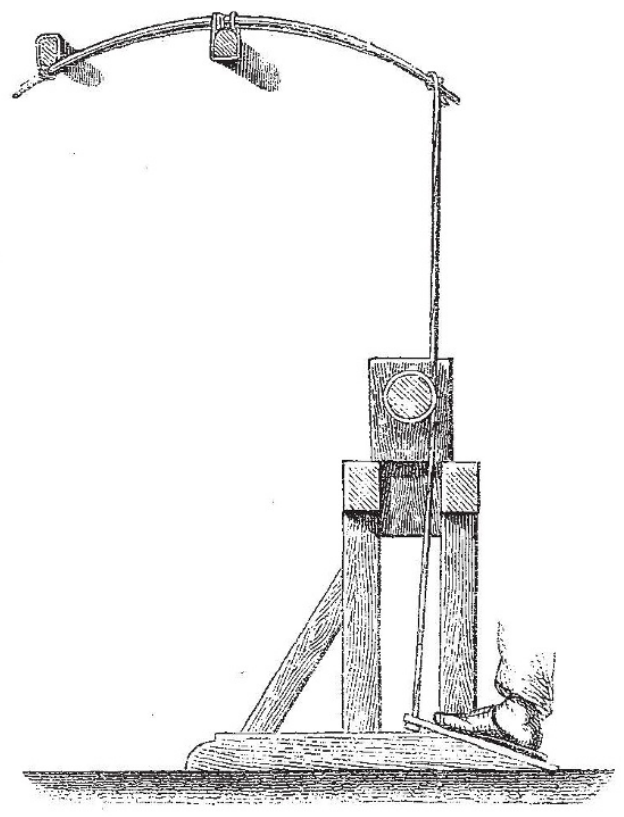

FIG. 5 .

manner being effected only with the assistance of the weight of one element, which must be greater than any disturbing force tending to cause motion in the direction opposite to that in which its weight acts. As examples of force-closed pairs are mentioned the plummer block of a water-wheel, which, owing to the weight of the wheel, constrains the motion without the complete closure of the pair by the addition of the cap, also railway wheels with the metals on which they roll.

We pass now to the History of Machine Development. "At the commencement of a study of machine development it is first of all necessary to know distinctly what it is that makes a machine complete or incomplete. It is only possible to judge of the completeness of a machine from the excellence of the work produced by it, if we are able to estimate separately what part of the result

I "The Kinematics of Machinery : Outlines of a Theory of Machines." By F. Reuleaux, Director of and Professor in the Königlichen Gewerbethademie in Berlin, Member of the Königl technischen Deputation fï (iewerbe. Translated and edited by Alex. B. W. Kennedy, C.E., Professor of Civil and Mechanical Engineering ir Unversity College, London. (bondon: Macmillan and Co., $\$ 876$.) Continued from p. 2T4 is due to the skill of the workman. Certain Indian fabrics, for instance, are of extraordinary excellence and delicacy, although they have been made in most defective looms; throughout the whole manufacture of these it is the weaver's dexterity that plays the most important part. In no machines can we absolutely do away with human action, if it be for no further purpose than to start and stop the process. It appears, therefore, that the most complete machine is the one fulfilling best its own work, and having for this share the greatest proportion of the whole task." The great use of tracing the history of the development of machines is, that the more clear the path along which real advance has come to pass can be laid down, the more clearly we are enabled to see the direction that must be taken by succeeding advances. Probably the earliest machine known is the fire-drill, used in very early days of the development of the human race for producing fire by its rapid rotation between the hands, being at the same time held in firm contact with another flat piece of wood. The improvements on this appear to have been pointing the fire-drill at the other end, enabling the vertical pressure to be supplied by an assistant by means of a flat piece pressed on the top of the drill,

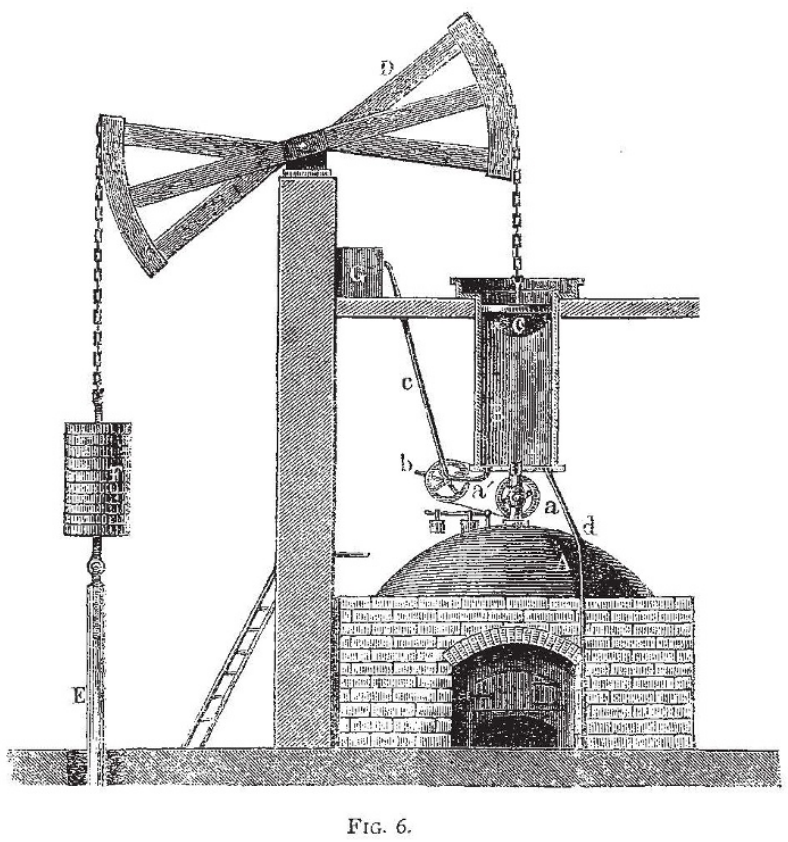

and communicating the rotation to the drill by means ot a cord wrapped once or twice round it. The applications of this tool seem to have been numerous, as with it hard woods, bone, horn, and even hard stones, appear to have been drilled, no doubt with the assistance of a supply of sand and water. From the fire-drill, probably after a very long interval, sprang the potter's wheel, and the earliest forms of turning-lathe turned in a similar manner; the principle is preserved to the present day in the bowdrill used for light metal-work. The origin of the screw and nut is lost in obscurity, but this pair of elements was certainly known to the Greeks and Romans; Prof. Reuleaux's suggestion of its origin, tracing it to the furedrill, is very ingenious, even if it is not the right one ; that with long-continued use of the drill, the cord may have worn spiral groves on the spindle, forming a screw-thread while the cord itself formed the nut. "The forms of the word screw in the Germanic languages greatly strengthen my suggestion. We cannot take into account the fact that in English and the Romance languages the characteristic portion of the screw is called 'thread' (filo, filet), 
for this name may have been subsequently given to it." Again, "The bow of the archer is a machinal organ in which energy is stored; the sensible force of the muscles is made latent in it, and it is this latent energy stored in the elastic bow which actually propels the arrow. In the ballista and catapult this principle receives still more extended application, for in them kinematic means are employed to store the energy of many men, so as to employ it concentrated with correspondingly increased effect. Later on the same principle extends itself to primary forces, and it is to-day more used than ever, from the tiny watch-work or the spring of a gun-lock, through innumerable mechanisms, up to the Armstrong accumulator or the air-vessels of the Mont Cénis borers." But it is from the kinematic point of view that the progress of the development of the machine is most accurately measured. What is the fundamental characteristic of the improvement that has been effected in the various stages of advance in the development of a machine? Prof. Reuleaux answers: "The line of progress is indicated in the manner of using force-closure or more particularly in the substitution of pair closure and the closure of the

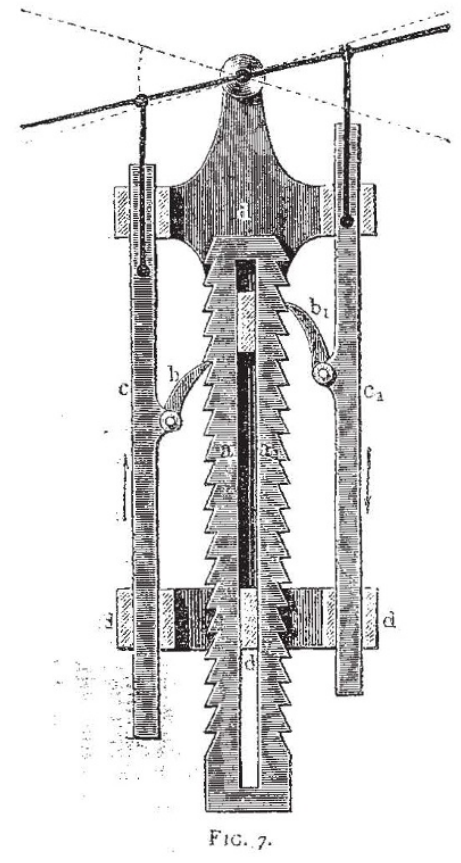

kinematic chains obtained by it for force-closure." In the fire-drill, which is an early form of turning-pair, we have not only force-closure by the action of the hands in the longitudinal direction, previous to the introduction of the bearing-piece on the top, but also forceclosure in the transverse direction by the hands. The invention of the string for turning the drill, itself a great advance, introduces another kinetic pair of elements, but still the string is constrained to keep in contact with the stick by the force-closure of the tension produced by the hands. In the earliest form of lathe with double headstocks, the force-closure of the double element is changed to pair-closure, marking a great advance in the development of the machine, and the string is worked in a more definite manner by one end being fastened to a bow or spring-beam, whilst the other is worked by the foot (Fig. 5).

"Thus simplicity or fewness of part does not itself constitute excellence as a machine, but increased exactness in the motions obtained, with diminished demands on the intelligence of any source of energy."

In more recent machinery, such as Newcomen's engine (Fig. 6), we see the connection of the beam $D$ and the pump-rod E, affected by the force-closure of the weight $\mathrm{F}$ acting on the chain, the connection of the piston $\mathrm{C}$, and the beam $\mathrm{D}$, affected by force-closure also, by the same weight, whilst the valve-gear was worked by hand.

By the invention of his nearly perfect parallel motion, Watt introduced kinematic pair and chain-closure into the steam-engine, as well as by the introduction of automatic valve-gear. Space will not permit us to give an account of the systems of kinematic notation proposed by Prof. Reuleaux, but it certainly is one of the most important chapters in the book, and will well repay a careful study, although some little time and trouble is evidently required to get the meaning of the various symbols impressed on the memory. When this has been done we have no doubt that it will amply compensate the learner. for his pains, by the much more ready comprehension he will obtain of complex mechanisms. We can only say, in the words of our author, "The reader need not fear that any continual alteration of his accustomed ideas will be demanded from him in making himself familiar with the system of contractions. For a scientific symbolic

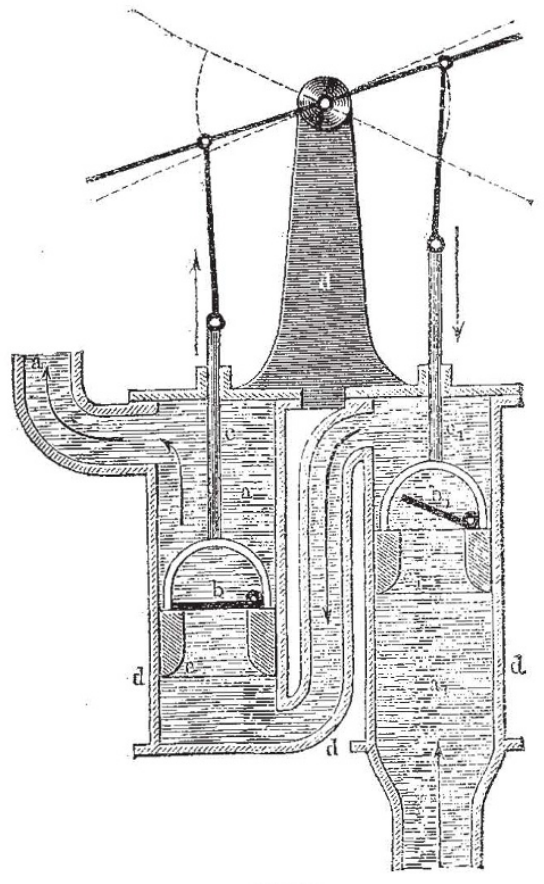

Fig 8.

notation is in essence nothing else than a systematised method of contraction-it is not a hieroglyphic system mysterious to the uninitiated." Under the head of anaIysis of chamber-crank chains, the various disc-engines, rotatory engines and blowers, of which such a larye and varied assortment has been from time to time invented, are described and figured, and our author states at the end of the long list so formed that the whole of the forms that have appeared are probably not exhausted, and that " a comparison of the machines described shows, indeed, that there are many easily constructed inversions of existing mechanisms which have not yet been proposed, and many analogies to existing forms which have not been tried; so we may look forward still to the production of whole series of chamber-crank trains by the never resting empirics. In Chapter xi. we come to the machine considered as a combination of constructive elements and the complete enumeration of them, and their systematic classification deserves particular attention. As an example of this classification we may give the double-acting ratchet train (Fig, 7) and the double- 
acting pump (Fig. 8); these are classed together, and a closer examination of the function and elements of each will immediately show the correctness of so doing. The two bars $c$ and $c$ in the ratchet train correspond with the two pump rods and buckets. The pumpbarrels $d d$ correspond with the guide frames $d d$ of the ratchet train, the valves $b$ and $b$ correspond with the pawls $b$ and $b$, while the water in the two barrels is the exact equivalent of the ratchet $a$ a. As the bar $c$ descends the pawl $b$ would pass over a certain number of teeth of the ratchet equal to the number in the length of stroke of $c$, if the bar $c$ was disconnected with the lever but as it is, during the descent of $c$, through a certain distance the ratchet is lifted an equal distance by the other pawl $b$; thus we see that each pawl passes over twice as many teeth of the ratchet as correspond to the length of its stroke. This has an exact parallel in the double-acting pump, for there also each bucket in its down stroke moves through a length of water equal to double the length of its stroke. The following is the outline of Prof. Reuleaux' Classification of Constructive Elements :-

Rigid Elements-

Joints (for forming links) such as rivets, keys, keyed joints.

Elements in pairs or in links, such as shafts and axles, levers, cranks, \&c.

Flectional Elements-

Tension organs by themselves and used with chainclosure, such as belts, cords.

Partners of pressure organs such as pistons and Springs. plungers, steam cylinders and pump barrels.

\section{Trains--}

Click-gear.

Brakes.

Movable couplings and clutches.

In conclusion we must say that the cuts illustrating the book, are much superior to those generally to be found in theoretical books on machinery, but they do not, of course, equal the elaborate working drawings to be found in certain books on machine design. In Fig. 169, p. 218 , the rope appears to have somewhat lost its way. The translator has done his work most admirably, and great must have been the ingenuity required to manufacture some of the names here presented for the first time to the English reader. In fact we could hardly imagine a book more difficult to translate, on account of the great number of specialiyconstructed words in it, nor do we remember having read ore in which the duties of the translator have been more successfully carried out. The book appears at a particularly suitable time, now that the beautiful and extensive collection of kinematic models by Prof. Reuleaux, designed by him and constructed especially to iliustrate his treatment of the theory of mechanism, is to be seen at the Loan Collection of Scientific Instruments at South Kensington.

\section{PERIGENESIS v. PANGENESIS-HAECKEL'S NEW THEORY OF HEREDITY}

UNDER the title "Perigenesis der Plastidule oder die Wellenzeugung der Lebenstheilchen," Prof. Haeckel has published quite recently a pamphlet containing an attempt to furnish a mechanical explanation of the elementary phenomena of reproduction which shall be more satisfactory than Mr. Darwin's ingenious and well-known theory of Pangenesis. I shall endeavour to show that Prof. Haeckel's theory is essentially that with which both English and German students of Mr. Herbert Spencer's works have long been familiar; and that it does not furnish a clearer explanation than does Mr. Darwin's Pangenesis, of the special facts of heredity which Mr. Darwin had in view.
Haeckel commences with a very concise statement of what is at present known as to the visible compo. sition of "plastids," those corpuscles of life-stuff called "cells" by Schleiden and Schwann, "elementary organisms" by B! ücke, "life-units" by Darwin. Most plastids possess a differentiated central kernel or nucleus, which again possesses one or more nucleoli. The substance of which the body of such a nucleated plastid or true cell is mainly composed is generally known by von Mohl's term, "pro oplasma." Haeckel proposes to distinguish the substance of the nucleus by the name "coccoplasma." In the simplest form of plastid, the "cytod," which is devoid of nucleus, and is exhibited by those lowly organisms known as Monera, by the young Gregarina (Ed. van Beneden), by the hyphæ of some Fungi, and by the ripe egg of all organisms (if we may judge from the resalts of the most recent researches), coccoplasm and protoplasm are not differentiated, but exist as one substance, which Haeckel, following Ed, van Beneden, distinguishes as "plasson." Whether these distinctions have a real value or not, is of no momeni for the question in hand. It is a widely-accepted doctrine-in fact, the fundamental generalisation on which Biology as a science rests-that the excessively complex chemical compound which forms the substance of plastids or life-units is the ultimate seat of those phenomena or manifestations of energy which distinguish living from lifeless things - to wit, growth by intus-susception, reproduction, adaptation, and continuity or hereditary transmission. Leaving Prof. Haeckel's pamphlet for a time, let us go back thirteen years.

As long ago as July, 1863, Mr. Herbert Spencer, in his "Principles of Biology," pointed out at considerable length (vol. i., p. 18r) that the assumption of definite forms, and the power of repair exhibited by organisms, is only to be brought into relation with other facts (thit is to say, so far explained) by the assumption that certain units composing the living substance or protoplasm of cells possess "polarity" similar to, but not identical with, that of the units which build up crystals. Mr. Spencer is careful to explain that by the term "polarity" we mean simply to axoid a circuitous expression, namely, the still unexplained power which these units have of arranging themselves into a special.form. He then points out that the units in question cannot be the molecules of the proximate chemical compounds which we obtain from protoplasmsuch as albumen, or fibrin, or geiatin, or even protein. Further he shows that they cannot be the cells or morphological units, since such organisms as the Rhizopods are not built up of cells, and since, moreover, "the formation of a cell is to some extent a manifestation of the peculiar power" under consideration. "If then," he continues, "this organic polarity can be possessed neither by the chemical units, nor the morphological units, we must conceive it as possesscd by certain intermediate units, which we may term physiological. There seems no alternative but to suppose that the chemical units combine into units immensely more complex than themselves, complex as they are; and that in each organism, the physiological units produced by this further compounding of higbly compound atoms, have a more or less distinctive character. We must conclude that in each case, some slight difference of compc sition in these units, leading to some s:i ht difference in their mutual play of forces, produces a difference in the form which the aggregate of them assumes."

Further on Mr. Spencer applies the hypothesis of physiological units to the explanation of the phenomena of heredily, introducing the subject by the following admirable remarks, which appear to me to assign in the most judicious manner, their true value to such hypotheses and to be as strictly applicable to later speculations as to his own. "A positive explanation of heredity is not to be expected in the present state of biology. We 